\title{
Properties of Alpha Monocerotid meteors from the observation of the 2019 outburst in the Czech Republic
}

\author{
Lukáš Shrbený, Jiří Borovička, Pavel Koten, Pavel Spurný, Rostislav Štork, Kamil Hornoch, and Vlastimil Vojáček
}

Astronomical Institute of the Czech Academy of Sciences, Fričova 298, 25165 Ondřejov, Czech Republic

Received June 2021 / Accepted August 2021

\begin{abstract}
We observed the predicted outburst of the Alpha Monocerotid (AMO) meteor shower on 2019 November 22 with our modernized video and photographic cameras. Due to the short duration and moderate intensity of the outburst, atmospheric trajectories and radiants were obtained for only ten meteors, seven of which included velocities, magnitudes, and orbits. In addition, one incomplete video spectrum was captured. The radiants and orbits were found to be compatible with that of the 1995 outburst. The spectrum confirmed that AMO meteoroids are deficient in sodium. Unlike any other meteor shower, meteor end heights were found to be distributed along a constant level of $90 \mathrm{~km}$ for all meteors with magnitudes between +4 and -2 and with atmospheric trajectory lengths up to $40 \mathrm{~km}$. We propose that Alpha Monocerotids were formed from a devolatilized and fragile cometary crust composed from relatively large fundamental grains.
\end{abstract}

Key words. meteors - meteoroids

\section{Introduction}

The Alpha Monocerotids (AMO, IAU \#246) is a meteor shower with a peak occurring around November 22 every year. The annual activity is low, but intense outbursts are occasionally produced. Five individual outbursts were observed in 1925, 1935 1985, 1995, and 2017 (Jenniskens et al. 1997, Jenniskens \& Odeh 2017; Roggemans et al. 2018). The observations in 1995 provided the first ten multi-station meteors with known radiants and heliocentric orbits giving the first evidence of the presence of a trail of a long-period comet. The peak zenith hourly rate (ZHR) of the 1995 AMO outburst was 500 (Jenniskens et al. 1997). Observations of the Cameras for Allsky Meteor Surveillance (CAMS) networks in 2017 provided 17 individual orbits of AMO meteors, even if no outburst was predicted (Roggemans et al. 2018). Median orbital elements of the majority of them (10 multi-station meteors were observed in the United Arab Emirates) are in good agreement with the observations obtained in 1995 (Jenniskens \& Odeh 2017). Four television spectra of AMO meteors were obtained in 1995 by Štork et al. (1998). They observed a very faint Na I line $(5892 \AA)$ and concluded that the material of AMO meteoroids contains a lower amount of volatile elements, at least sodium. Borovička et al. (2005) classified AMO meteors near the boundary between Na-poor and $\mathrm{Na}$-free meteoroids according to their spectral properties. Jenniskens et al. (1997) noted that Alpha Monocerotids have relatively low ends of their atmospheric trajectories compared to other cometary meteoroids with similar velocities (e.g., Perseids), and they are therefore stronger and might lack volatiles.

Lyytinen \& Jenniskens (2003) found that only encounters with one-revolution trails can explain the observed outburst duration of 40 minutes. The best solution for the unknown orbital period of the parent comet was 650 years. The original calculation showed the trail will pass far from the Earth's orbit in 2019. Recently, Jenniskens \& Lyytinen (2019) re-evaluated this result assuming a shorter orbital period of 500 years, which moved the trail closer to the Earth. They predicted similar or even higher peak rate in comparison with the 1995 encounter. The 2019 encounter was expected at solar longitude $239.308^{\circ}$; that is, on November 22, 4h $50 \mathrm{~m}$ UT with a full width at half maximum (FWHM) of only 0.29 hours.

Following that prediction, we decided to organize a video and digital photography campaign to observe the outburst. The campaign was successful, though the number of observed AMO meteors was not high, and we report the results here. Section 2 is devoted to the description of the observations. The obtained data are described in Section 3 and analyzed from various points of view in Section 4 The implications are discussed in Section 5

\section{Observations}

The peak timing was more favorable for Western Europe than for Central Europe; nevertheless, most of the outburst should still be visible before the beginning of dawn from Central Europe. The Moon was only $20 \%$ illuminated, so not creating much of a disturbance. Therefore, we planned to carry out the double station video observation within the Czech Republic. Due to the weather forecast, we finally selected two mountain stations in Southern Bohemia, which proved to be a lucky choice as almost the whole country was overcast that morning.

The first station was Churáňov, which is a regular station of the Czech part of the European Fireball Network (EN), equipped with Digital Autonomous Fireball Observatory (DAFO) and its spectral equivalent (SDAFO) (see Spurný et al. (2017) and Borovička et al. (2019) for DAFO and SDAFO descriptions, respectively). Both observatories use two Canon 6D Digital Single-Lens Reflex (DSLR) cameras to take 35 respective $30 \mathrm{~s}$ long exposures of the sky. DAFO uses F3.5, $8 \mathrm{~mm}$ fish-eye lens, while SDAFO uses F2.8, $15 \mathrm{~mm}$ lens. DAFO is equipped with a liquid crystal shutter (LCD) for the measurement of meteor 
Table 1. Photographic and video cameras used during AMO 2019 observation. MLM is meteor limiting magnitude, fps is frames per second. Camera codes: $\mathrm{C}$ is Churáňov, $\mathrm{M}$ Myslivna, K Křrišt' anov, $v$ is regular video camera, sp is spectral video camera, D is photographic DAFO, $\mathrm{S}$ is photographic SDAFO, sv is supplementary video camera, and number is focal length of supplementary photographic camera ( $35 \mathrm{~mm}$ equivalent).

\begin{tabular}{l|cccccc}
\hline camera & $\begin{array}{c}\text { Resolution } \\
\text { (pixels) }\end{array}$ & $\begin{array}{c}\text { MLM } \\
\text { (mag) }\end{array}$ & $\begin{array}{c}\text { fps or } \\
\text { sector }\end{array}$ & $\begin{array}{c}\text { FOV } \\
\text { (deg) }\end{array}$ & Site & code \\
\hline \multicolumn{1}{l}{ Video } & & & & & & \\
DMK23G445 direct & $1280 \times 960$ & 6 & 30 & 20 & Churáňov & Cv \\
DMK23G445 spectral & $1280 \times 960$ & 4 & 30 & 30 & Churáňov & Csp \\
DMK23G445 direct & $1280 \times 960$ & 6 & 30 & 20 & Myslivna & Mv \\
ZWO ASI174MM & $1936 \times 1216$ & +1.5 & 30 & 85 & Myslivna & Msv \\
$\quad$ & & & & & & \\
Photographic & $5472 \times 3648$ & -1 & 16 & fish-eye & Churáňov & CD \\
DAFO & $5472 \times 3648$ & 1 & - & diagonal fish-eye & Churáňov & CS \\
SDAFO & $5472 \times 3648$ & +0.5 & - & fish-eye & Myslivna & M10 \\
Canon 6D & $4272 \times 2848$ & +1.5 & - & 70 & Myslivna & M25 \\
Canon 450D & $6240 \times 4160$ & +2.5 & - & 95 & Křišt'anov & K16 \\
Canon 6D II & $5184 \times 3456$ & +2.5 & - & 80 & Křišt'anov & K21 \\
Canon 550D & & & & & &
\end{tabular}

velocities. SDAFO is equipped with a holographic grating to take spectra of bright fireballs. Nevertheless, direct images (zero orders) of meteors can be used to measure meteor trajectories, though without velocity information. Thanks to its lens properties, SDAFO is more sensitive than DAFO but it does not cover the whole sky (it is a diagonal fish-eye).

For the AMO campaign, two image-intensified video cameras were additionally run at the Churáňov station, one for direct imaging and one for spectroscopy. Both instruments contain a digital DMK23G445 GigE monochromatic camera, a CCTV Basler C125 F1.8, 8 mm lens, and a Mullard XX1332 image intensifier. The camera is providing a spatial resolution of $1280 \times 960$ pixels, time resolution up to 30 frames per second (fps), and a dynamic range of 8 bits (Koten et al. 2020). The fundamental issue was the choice of the main lens for the direct camera. We decided to use a long focal Canon F2, $135 \mathrm{~mm}$ objective lens providing high sensitivity and a field of view (FOV) of about 20 degrees in diameter. Such a relatively small FOV may result in a lower number of detections but provides precise orbits of the meteors. Because of a high predicted peak rate and recent experience with the same equipment used for the 2018 Draconid outburst observation (Koten et al.2020), we estimated a recording of 10 to 20 AMO meteors, which can provide us with an insight into the comet orbit. The Jupiter F2, $85 \mathrm{~mm}$ objective lens, together with a blazed spectral grating with 600 grooves per mm, were used for the spectral video observation. The camera is sensitive to wavelengths between 3800 and $9000 \AA$. Again, zero-order detections could be used for trajectory and velocity measurements.

Since all other EN stations had poor weather conditions, we set up a temporary observing site at the Myslivna Mountain, about $90 \mathrm{~km}$ southeast of Churáňov. That site was equipped with an identical direct imaging video camera to that of Churáňov. Spectral observations were not performed, but a supplementary video camera of type ZWO ASI174MM with a wide FOV (about 85 degrees horizontally) was operated to record brighter meteors. For common detections with Churáňov's DAFO, another Canon 6D DSLR camera with (almost) all-sky view $(10 \mathrm{~mm}$ lens) was used (without LCD shutter). This camera was supplemented with a Canon 450D camera equipped with a $25 \mathrm{~mm}$ lens ( $35 \mathrm{~mm}$ equivalent focal length) providing a FOV of $70 \mathrm{de}$ grees. In addition, visual observations were performed by one of us $(\mathrm{KH})$ at Myslivna.
Finally, a third backup observing site was set up at Křrišt'anov, between Churáňov and Myslivna. Two DSLR cameras with $16 \mathrm{~mm}$ and $21 \mathrm{~mm}$ lenses $(35 \mathrm{~mm}$ equivalent focal length) were operated here. The parameters of all used video and photographic cameras, such as sensor pixel resolution, approximate limiting magnitude for meteors, field of view, and the frame rate (video) or shutter frequency (DAFO) are given in Table 1 . The coordinates of the observing sites are given in Table 2.

The observation period was from 2:50 to 5:40 UT under clear sky throughout almost the whole period. Only high cirrus clouds shortly passed through the FOV of our video cameras. The end of the period was affected by dawn.

The data records were inspected manually in order not to miss even very faint meteors. Meteor images and videos were measured and reduced by our standard methods (Spurný et al. 2017, Koten et al. 2020).

\section{Data description}

Three of us (JB, PS, KH) witnessed the 1995 outburst (Borovička \& Spurný 1995; Znojil \& Hornoch 1995), and our impression of the 2019 activity was definitely weaker. Nevertheless, KH, who is an experienced visual observer, counted 44 AMO meteors between $4 \mathrm{~h} 26 \mathrm{~m}$ and $5 \mathrm{~h} 23 \mathrm{~m}$ UT, 16 of them during the ten-minute interval centered at $4 \mathrm{~h} 50 \mathrm{~m}$ UT. The starlimiting magnitude was near 6.5 at that time.

Altogether, up to 50 different meteors were detected by at least one of the narrow field video cameras, and 18 of them were double-station cases. However, only three of them belong to the AMO shower, as measurements and calculations finally showed. Interestingly, only one of the three AMO meteors was fainter than magnitude +2 . Among the other 15 meteors, 12 were fainter than +2 mag. We are aware that the number of meteors is not sufficient for good statistics, but it looks like there was a lack of AMO meteors fainter than +2 mag. Our visual data contain faint AMO meteors down to magnitude +6 , but in smaller proportions than for sporadic meteors.

Seven multi-station AMO meteors were recorded by photographic cameras; only one of them by DAFO, but three of them by the wide-field video (which recorded four AMO meteors in total). The velocity could therefore be computed for four photographic meteors. Photometry could be done for meteors with velocity measurements, either from DAFO or from wide-field 
Table 2. Geographical coordinates of observation sites. The comment column states the camera used.

\begin{tabular}{|c|c|c|c|c|}
\hline Station & Longitude E & Latitude $\mathrm{N}$ & Altitude $(\mathrm{km})$ & comment \\
\hline \multicolumn{5}{|l|}{ Video } \\
\hline Churán̆ov & 13.61483 & 49.06836 & 1.118 & direct $(\mathrm{Cv})$, spectral (Csp) \\
\hline Myslivna & 14.68723 & 48.63044 & 1.012 & direct $(\mathrm{Mv})$, wide fov (Msv) \\
\hline \multicolumn{5}{|c|}{ Photographic } \\
\hline Churáňov & 13.61495 & 49.06843 & 1.119 & DAFO (CD), SDAFO (CS) \\
\hline Myslivna & 14.68714 & 48.63041 & 1.012 & all-sky (M10), wide fov (M25) \\
\hline Křišt'anov & 13.99785 & 48.90794 & 0.885 & two wide fov (K16, K21) \\
\hline
\end{tabular}

video. The wide-field video photometry should be, nevertheless, taken as approximative.

The list of all ten multi-station AMO meteors is given in Table 3. The quality of the three video meteors is rather low. The meteor at 4:47:47 UT is distinct in the FOV but close to the edge of the FOV at both sites. This meteor is the best among the three. The meteor at 4:50:30 UT is very faint and hardly visible above the background, but closer to the center of the FOV. The meteor at 4:51:24 UT has the beginning out of the FOV and only the very end of the meteor is visible on the very edge of the FOV at Myslivna. This meteor would be impossible to calculate without additional data. Fortunately, the meteor was also recorded by the wide-field video camera (Msv), which has a lower level of sensitivity, in the center of its FOV. This is the reason why the beginning of this meteor, which was the brightest of the three, is at lower altitude than the other two. The photographic meteors represent a more uniform sample in this respect since all of them were recorded by SDAFO.

The spectral video camera recorded one AMO spectrum. Unfortunately, though the camera sensitivity range is from 3700 to $9000 \AA$, the record contains only the wavelengths from 5360 to $9000 \AA$, since the spectrum was out of the camera field of view for wavelengths shorter than $5360 \AA$. The spectrum belongs to the meteor at 5:01:51 UT, which was observed photographically. In the following section, we present the results of the data analysis. In particular, we concentrate on atmospheric heights, radiants, orbits, and the spectrum.

\section{Results}

\subsection{Atmospheric trajectories and heights}

Meteor beginning and end heights, trajectory lengths, and zenith distances of radiants are given in Table 3 Since all meteors occurred during a short time interval, their trajectory slopes are similar. Two values of beginning and end heights are listed for photographic meteors: the values from all detections, and the values based on SDAFO only. The first set depends on the type of instrument, while the second set is more homogeneous. The beginning and end heights of all AMO 2019 meteors are shown in Figure 1 as function of the length of the atmospheric trajectory. The dependencies based on SDAFO are shifted to shorter trajectories, as expected. It is reasonable to assume that higher initial mass of the meteoroids implies longer atmospheric trajectory (in case of the same velocity, slope, and material composition). We can then see the same dependency for beginning heights as that observed for other meteor showers with a cometary origin (see e.g., Koten et al. 2004), that is the beginning height increases with increasing meteoroid mass or is constant. The end height decreases with increasing meteoroid mass in all other showers (Koten et al. 2004), but it is not the case of our AMO meteors. We see slightly increasing or constant dependency. If we do



Fig. 1. Beginning (blue symbols) and end (red symbols) heights of the photographic meteors as a function of the length of the atmospheric trajectory. Solid lines show linear dependencies of heights $H_{\text {beg }}$ and $H_{\text {end }}$ on observed length of atmospheric trajectory, $L$, dashed lines show linear dependencies of heights $H_{\text {begs }}$ and $H_{\text {end }}$ observed by spectral photographic camera at station Churáňov (CS in Table 1) on the length observed by the CS camera. Our three video meteors are plotted by diamonds for comparison. Values of beginning and terminal heights of AMO meteors observed by CAMS (triangles) and terminal heights of Perseid meteors (green stars) are also shown for easy comparison.

not include the longest meteor 4:58:28 UT, the dependency is constant within the range of errors and the end heights are distributed along constant height $90.0 \pm 0.7 \mathrm{~km}$ (if all photographic AMO meteors are used the terminal height is $90.4 \pm 1.1 \mathrm{~km}$ and if also video meteors are used the height is $90.4 \pm 1.3 \mathrm{~km}$ ). It is improbable that the terminal height of the 4:58:28 UT meteor could be at a lower altitude, since it was recorded by the sensitive photographic camera from Křišt' anov.

It is important to note that the dependency is based on seven meteors only. So, we searched for any AMO meteor with available atmospheric trajectory for comparison. We only found a catalog of video meteors of Cameras for All-sky Meteor Surveillance (CAMS) by Jenniskens et al. (2018). The last available catalog of CAMS data is version 3, with multi-station meteors recorded between October 2010 and December 2016. We found 17 meteors designated as AMO. We then used the mean AMO orbit published by Jenniskens et al. (1997) as a reference to ver- 
Table 3. Atmospheric trajectories of multi-station AMO meteors observed on 2019 November $22 . \Delta \mathrm{t}$ is an uncertainty in the beginning time, $H_{\text {beg }}$ and $H_{\text {end }}$ are observed beginning and terminal heights, $H_{\text {begs }}$ and $H_{\text {end }}$ are beginning and terminal heights observed by a photographic spectral camera at station Churáňov (CS), L is the observed length of the atmospheric trajectory, $Z D_{R}$ is the zenith distance of the radiant at $H_{e n d}, M_{a b s}$ is the absolute (100 km distance) magnitude, $v_{\text {inf }}$ is the initial velocity, $\mathrm{N}$ is the number of stations where the meteor was observed (number in parentheses is number of stations used for the trajectory solution), and Cam refers to cameras by which the meteor was recorded (abbreviations follow the designation as in Table 1 .

\begin{tabular}{|c|c|c|c|c|c|c|c|c|c|c|c|}
\hline $\begin{array}{l}\text { Time } \\
\text { (UT) }\end{array}$ & $\begin{array}{l}\Delta \mathrm{t} \\
(\mathrm{s})\end{array}$ & $\begin{array}{l}H_{b e g} \\
(\mathrm{~km})\end{array}$ & $\begin{array}{c}H_{\text {begS }} \\
(\mathrm{km})\end{array}$ & $\begin{array}{l}H_{\text {end }} \\
(\mathrm{km})\end{array}$ & $\begin{array}{r}H_{\text {endS }} \\
(\mathrm{km})\end{array}$ & $\begin{array}{c}\mathrm{L} \\
(\mathrm{km})\end{array}$ & $\begin{array}{l}Z D_{R} \\
(\mathrm{deg})\end{array}$ & $\begin{array}{c}M_{a b s} \\
(\mathrm{mag})\end{array}$ & $\begin{array}{c}v_{\text {inf }} \\
\left(\mathrm{km} \mathrm{s}^{-1}\right)\end{array}$ & $\mathrm{N}$ & Cam \\
\hline \multicolumn{12}{|c|}{ Video meteors } \\
\hline $4: 47: 47$ & $<1$ & 100.949 & - & 92.172 & - & 15.30 & 55.06 & +2.0 & $63.7 \pm 0.3$ & 2 & $\mathrm{Cv}, \mathrm{Mv}$ \\
\hline $4: 50: 30$ & $<1$ & 100.080 & - & 90.660 & - & 16.16 & 54.42 & +4.1 & $64.4 \pm 1.3$ & 2 & $\mathrm{Cv}, \mathrm{Mv}$ \\
\hline $4: 51: 24$ & $<1$ & $97.750^{a}$ & - & 88.269 & - & 16.43 & 54.8 & +1.2 & $62.8 \pm 0.3$ & 2 & $\mathrm{Cv}, \mathrm{Mv}, \mathrm{Msv}$ \\
\hline \multicolumn{12}{|c|}{ Photographic meteors } \\
\hline $4: 40: 53$ & \pm 6 & 97.898 & 97.898 & 88.985 & 90.654 & 14.68 & 52.66 & - & - & 2 & CS, M10, M25 \\
\hline $4: 44: 22$ & \pm 5 & 100.594 & 100.594 & 90.713 & 90.713 & 16.26 & 52.62 & - & - & 3 & $\mathrm{CS}, \mathrm{M} 25, \mathrm{~K} 16$ \\
\hline $4: 47: 20$ & $<1$ & 95.176 & 95.126 & 90.038 & 90.741 & 8.63 & 53.83 & -0.9 & $62.7 \pm 0.3$ & $3(2)^{b}$ & CS, Msv, K16 \\
\hline $4: 58: 28$ & \pm 1 & 109.970 & 106.926 & 92.451 & 92.837 & 30.23 & 54.68 & -2.4 & $62.93 \pm 0.12$ & 3 & $\mathrm{CD}, \mathrm{CS}, \mathrm{M} 10, \mathrm{M} 25, \mathrm{~K} 21$ \\
\hline $5: 01: 51$ & $<1$ & 101.757 & 101.757 & 90.964 & 92.666 & 19.20 & 55.86 & -1.0 & $63.2 \pm 0.4$ & 2 & CS, Csp, Msv \\
\hline $5: 07: 31$ & $<1$ & 99.995 & 98.717 & 89.588 & 91.489 & 18.51 & 55.92 & -0.8 & $63.0 \pm 0.3$ & 2 & CS, M10, Msv \\
\hline 5:10:09 & \pm 6 & 97.134 & 95.747 & 89.732 & 89.732 & 13.25 & 56.08 & - & - & 2 & $\mathrm{CS}, \mathrm{M} 10$ \\
\hline
\end{tabular}

Notes: a) beginning of video meteor at 4:51:24 UT was not in the FOV of our regular cameras, the beginning is from the supplementary ZWO camera with lower sensitivity; b) record from Krišt' anov was not used since the meteor was recorded on the very edge of the FOV and the trajectory shows systematic shift of $70 m$ in comparison to final solution.

ify the orbital similarity according to the procedure of Southworth \& Hawkins (1963). We removed one meteor with a value of $D_{S H}>0.15$. Atmospheric trajectories of all our AMO meteors are shorter than $40 \mathrm{~km}$, so we only used 12 meteors from the CAMS catalog for comparison. The direct comparison would be better if only meteors with similar zenith distances of the radiant are used, but the application of this condition would lead to only one meteor for comparison. These 12 meteors are plotted in Figure 1 with triangles. The beginning heights correspond to our data, and the terminal heights are distributed along a constant height of $90 \pm 3 \mathrm{~km}$, which also corresponds to our observation. We can conclude that terminal heights of AMO meteors with atmospheric trajectories shorter than $40 \mathrm{~km}$ are distributed along a constant height of $90 \mathrm{~km}$. It is important to note that there are four AMO meteors in the CAMS catalog with atmospheric trajectories longer than $40 \mathrm{~km}$. Their terminal heights decrease with increasing length of the atmospheric trajectory, as is observed for other meteor showers with cometary origin (Koten et al. 2004).

The terminal heights of AMO meteors shorter than $40 \mathrm{~km}$ were also directly compared to the terminal heights of Perseids in Fig. 1. Perseids have similar atmospheric velocities $\left(60 \mathrm{~km} \mathrm{~s}^{-1}\right)$. We selected 31 video Perseids from the data published by Koten et al. (2004). Perseids with atmospheric trajectories shorter than $40 \mathrm{~km}$ and zenith distances of the radiant in the 50-60 degree range (corresponding to our AMO meteors) were used. Their terminal heights decrease with increasing length of the atmospheric trajectory. Moreover, most Perseid meteors terminate at higher altitudes in comparison with AMO meteors of the same length.

\subsection{Radiants and orbits}

The radiants of our AMO meteors are plotted in Figure 2 and listed in Table 4. The area of the radiant is compact, and the mean radiant (weighted average) of the photographic meteors corresponds well to the radiant observed during the 1995 AMO outburst (Jenniskens et al. 1997). The comparison of AMO radiant data published so far is presented in Table 5.

Heliocentric orbits could be computed for seven meteors with measured velocities. The measurement of atmospheric ve- locity is always challenging in the case of fast and short meteors, especially for double-station meteors. Due to a narrow field of view, we were able to determine the initial velocities of video meteors with a standard deviation bellow or slightly above $1 \mathrm{~km} \mathrm{~s}^{-1}$ (Table 3). The mean (weighted average) initial velocity of our three video meteors is $63.3 \pm 0.4 \mathrm{~km} \mathrm{~s}^{-1}$.

Atmospheric velocities of photographic meteors are based on two different instruments. The meteor at 4:58:28 UT was recorded by DAFO, and the other three meteors were recorded by the wide-field video camera. Short atmospheric trajectories lead to the initial velocities with a standard deviation of few tenths of $\mathrm{km} \mathrm{s}^{-1}$ (Table 3). The mean (weighted average) initial velocity of our four photographic meteors is $62.99 \pm 0.06 \mathrm{~km} \mathrm{~s}^{-1}$. The weighted average initial velocity of all seven AMO meteors is $63.00 \pm 0.15 \mathrm{~km} \mathrm{~s}^{-1}$.

Orbital elements of all AMO 2019 meteors and their weighted averages are presented in Table 4 . It was not possible to determine a reliable semi-major axis on the basis of such small number of short and fast meteors. Even if the radiant is well determined, the uncertainty in initial velocity (velocities $62.7-64.4 \mathrm{~km} \mathrm{~s}^{-1}$ ) results in orbits of either short-period or long-period comets or even hyperbolic orbits. From the nature of AMO outbursts, it is known that only encounters with a onerevolution trail of an unknown long-period comet can explain the shower (Lyytinen \& Jenniskens 2003), so only elliptical orbits are possible. The weighted average value of the semi-major axis is $21 \pm 6 \mathrm{AU}$, which gives an orbital period of around 100 years. However, longer periods would be consistent with our data as well, so this can be taken as a lower limit. Jenniskens (2006) also used the available AMO observations to determine the lower limit of the semi-major axis. He concluded that a $>28 \mathrm{AU}$ (period $>150$ years).

\subsection{The spectrum}

The single recorded spectrum is shown in Figure 3, where it is also compared with the spectrum of one Perseid recorded with the same equipment. In the covered spectral range, the line of sodium Na I at $5892 \AA$ is usually dominant along with the atmospheric lines of $\mathrm{O}$ I and $\mathrm{N}$ I and $\mathrm{N}_{2}$ in the region between 7000 
Table 4. Radiants and orbital elements of multi-station AMO meteors observed on 2019 November 22.

\begin{tabular}{|c|c|c|c|c|c|c|c|c|c|c|}
\hline $\begin{array}{l}\text { Time } \\
\text { (UT) }\end{array}$ & $\begin{array}{l}\text { R.A. } \\
\text { (deg) }\end{array}$ & $\begin{array}{l}\text { Decl. } \\
\text { (deg) }\end{array}$ & $\begin{array}{l}\text { R.A. } G \\
(\operatorname{deg})\end{array}$ & $\begin{array}{l}\operatorname{Decl}_{G} \\
(\operatorname{deg})\end{array}$ & $\begin{array}{c}\mathrm{v}_{G} \\
\left(\mathrm{kms}^{-1}\right)\end{array}$ & $\mathrm{e}$ & $\begin{array}{c}\mathrm{q} \\
(\mathrm{AU})\end{array}$ & $\begin{array}{c}\omega \\
(\mathrm{deg})\end{array}$ & $\begin{array}{c}\mathrm{i} \\
\text { (deg) }\end{array}$ & $\mathrm{T}_{J}$ \\
\hline \multicolumn{11}{|c|}{ Video meteors } \\
\hline 4:47:47 & $\begin{array}{c}117.366 \\
+0.016\end{array}$ & $\begin{array}{c}0.84 \\
\pm 0.05\end{array}$ & $\begin{array}{c}116.686 \\
\pm 0.017\end{array}$ & $\begin{array}{c}0.47 \\
\pm 0.05\end{array}$ & $\begin{array}{l}62.9 \\
\pm 0.3\end{array}$ & $\begin{array}{c}1.016 \\
+0.015\end{array}$ & $\begin{array}{c}0.491 \\
+0.006\end{array}$ & $\begin{array}{r}89.8 \\
+1.1\end{array}$ & $\begin{array}{r}133.21 \\
+0.26\end{array}$ & -0.77 \\
\hline $4: 50: 30$ & $\begin{array}{l}117.67 \\
\pm 0.05\end{array}$ & $\begin{array}{c}1.49 \\
\pm 0.11\end{array}$ & $\begin{array}{c}116.99 \\
\pm 0.05\end{array}$ & $\begin{array}{c}1.13 \\
\pm 0.11\end{array}$ & $\begin{array}{l}63.6 \\
\pm 1.3\end{array}$ & $\begin{array}{c}1.04 \\
\pm 0.06\end{array}$ & $\begin{array}{c}0.495 \\
\pm 0.021\end{array}$ & $\begin{array}{l}89 \\
\pm 4\end{array}$ & $\begin{array}{l}135.1 \\
\pm 0.9\end{array}$ & -1.0 \\
\hline $4: 51: 24$ & $\begin{array}{l}117.81 \\
\pm 0.03\end{array}$ & $\begin{array}{c}0.92 \\
\pm 0.09\end{array}$ & $\begin{array}{l}117.11 \\
\pm 0.03\end{array}$ & $\begin{array}{c}0.54 \\
\pm 0.09\end{array}$ & $\begin{array}{l}62.0 \\
\pm 0.3\end{array}$ & $\begin{array}{c}0.969 \\
\pm 0.012\end{array}$ & $\begin{array}{c}0.481 \\
\pm 0.005\end{array}$ & $\begin{array}{l}92.4 \\
\pm 1.0\end{array}$ & $\begin{array}{l}133.17 \\
\pm 0.27\end{array}$ & -0.25 \\
\hline WA & $\begin{array}{l}117.48 \\
\pm 0.16 \\
\end{array}$ & $\begin{array}{c}0.94 \\
\pm 0.18 \\
\end{array}$ & $\begin{array}{l}116.81 \\
\pm 0.16 \\
\end{array}$ & $\begin{array}{c}0.57 \\
\pm 0.19 \\
\end{array}$ & $\begin{array}{l}62.5 \\
\pm 0.4 \\
\end{array}$ & $\begin{array}{c}0.989 \\
\pm 0.022\end{array}$ & $\begin{array}{c}0.485 \\
\pm 0.004\end{array}$ & $\begin{array}{l}91.1 \\
\pm 1.1\end{array}$ & $\begin{array}{l}133.3 \\
\pm 0.5\end{array}$ & $\begin{array}{l}-0.5 \\
\pm 0.7\end{array}$ \\
\hline \multicolumn{11}{|c|}{ Photographic meteors } \\
\hline $4: 40: 53$ & $\begin{array}{l}117.84 \\
\pm 0.04\end{array}$ & $\begin{array}{c}1.17 \\
\pm 0.04\end{array}$ & & & & & & & & \\
\hline $4: 44: 22$ & $\begin{array}{l}117.86 \\
\pm 0.05\end{array}$ & $\begin{array}{c}1.34 \\
\pm 0.07\end{array}$ & & & & & & & & \\
\hline 4:47:20 & $\begin{array}{l}117.75 \\
\pm 0.06\end{array}$ & $\begin{array}{c}1.03 \\
\pm 0.11\end{array}$ & $\begin{array}{l}117.07 \\
\pm 0.06\end{array}$ & $\begin{array}{c}0.65 \\
\pm 0.011\end{array}$ & $\begin{array}{l}61.9 \\
\pm 0.3\end{array}$ & $\begin{array}{c}0.967 \\
\pm 0.011\end{array}$ & $\begin{array}{c}0.477 \\
\pm 0.005\end{array}$ & $\begin{array}{l}92.9 \\
\pm 0.9\end{array}$ & $\begin{array}{l}133.3 \\
\pm 0.3\end{array}$ & -0.22 \\
\hline 4:58:28 & $\begin{array}{c}117.715 \\
\pm 0.020\end{array}$ & $\begin{array}{c}1.21 \\
\pm 0.04\end{array}$ & $\begin{array}{l}117.021 \\
\pm 0.020\end{array}$ & $\begin{array}{c}0.84 \\
\pm 0.04\end{array}$ & $\begin{array}{l}62.11 \\
\pm 0.12\end{array}$ & $\begin{array}{c}0.975 \\
\pm 0.005\end{array}$ & $\begin{array}{c}0.4767 \\
\pm 0.0022\end{array}$ & $\begin{array}{l}92.7 \\
\pm 0.4\end{array}$ & $\begin{array}{c}133.65 \\
\pm 0.11\end{array}$ & -0.32 \\
\hline 5:01:51 & $\begin{array}{l}117.94 \\
\pm 0.06\end{array}$ & $\begin{array}{c}1.23 \\
\pm 0.09\end{array}$ & $\begin{array}{c}117.24 \\
\pm 0.06\end{array}$ & $\begin{array}{c}0.86 \\
\pm 0.09\end{array}$ & $\begin{array}{l}62.4 \\
\pm 0.4\end{array}$ & $\begin{array}{c}0.983 \\
\pm 0.018\end{array}$ & $\begin{array}{c}0.484 \\
\pm 0.008\end{array}$ & $\begin{array}{l}91.6 \\
\pm 1.4\end{array}$ & $\begin{array}{l}134.1 \\
\pm 0.4\end{array}$ & -0.4 \\
\hline $5: 07: 31$ & $\begin{array}{c}117.790 \\
\pm 0.017\end{array}$ & $\begin{array}{c}1.25 \\
\pm 0.04\end{array}$ & $\begin{array}{l}117.087 \\
\pm 0.018\end{array}$ & $\begin{array}{c}0.88 \\
\pm 0.04\end{array}$ & $\begin{array}{l}62.2 \\
\pm 0.3\end{array}$ & $\begin{array}{c}0.977 \\
\pm 0.012\end{array}$ & $\begin{array}{c}0.478 \\
\pm 0.005\end{array}$ & $\begin{array}{l}92.5 \\
\pm 1.0\end{array}$ & $\begin{array}{l}133.84 \\
\pm 0.23\end{array}$ & -0.35 \\
\hline 5:10:09 & $\begin{array}{l}117.99 \\
\pm 0.07\end{array}$ & $\begin{array}{c}0.97 \\
\pm 0.08\end{array}$ & & & & & & & & \\
\hline WA & $\begin{array}{l}117.78 \\
\pm 0.04\end{array}$ & $\begin{array}{c}1.20 \\
\pm 0.04\end{array}$ & $\begin{array}{l}117.07 \\
\pm 0.04\end{array}$ & $\begin{array}{c}0.85 \\
\pm 0.04\end{array}$ & $\begin{array}{l}62.11 \\
\pm 0.07\end{array}$ & $\begin{array}{c}0.9745 \\
\pm 0.0021\end{array}$ & $\begin{array}{c}0.4773 \\
\pm 0.0013\end{array}$ & $\begin{array}{l}92.64 \\
\pm 0.20\end{array}$ & $\begin{array}{c}133.67 \\
\pm 0.10\end{array}$ & $\begin{array}{l}-0.31 \\
\pm 0.11\end{array}$ \\
\hline \multicolumn{11}{|c|}{ All meteors } \\
\hline WA & $\begin{array}{l}117.66 \\
\pm 0.08\end{array}$ & $\begin{array}{c}1.15 \\
\pm 0.05 \\
\end{array}$ & $\begin{array}{l}116.95 \\
\pm 0.08\end{array}$ & $\begin{array}{c}0.77 \\
\pm 0.07\end{array}$ & $\begin{array}{l}62.18 \\
\pm 0.15 \\
\end{array}$ & $\begin{array}{c}0.977 \\
\pm 0.007\end{array}$ & $\begin{array}{c}0.4788 \\
\pm 0.0025 \\
\end{array}$ & $\begin{array}{l}92.4 \\
\pm 0.5 \\
\end{array}$ & $\begin{array}{c}133.59 \\
\pm 0.13\end{array}$ & $\begin{array}{l}-0.34 \\
\pm 0.19 \\
\end{array}$ \\
\hline
\end{tabular}

Note: WA stands for weighted average. The uncertainties of one standard deviation are given in rows below the values.
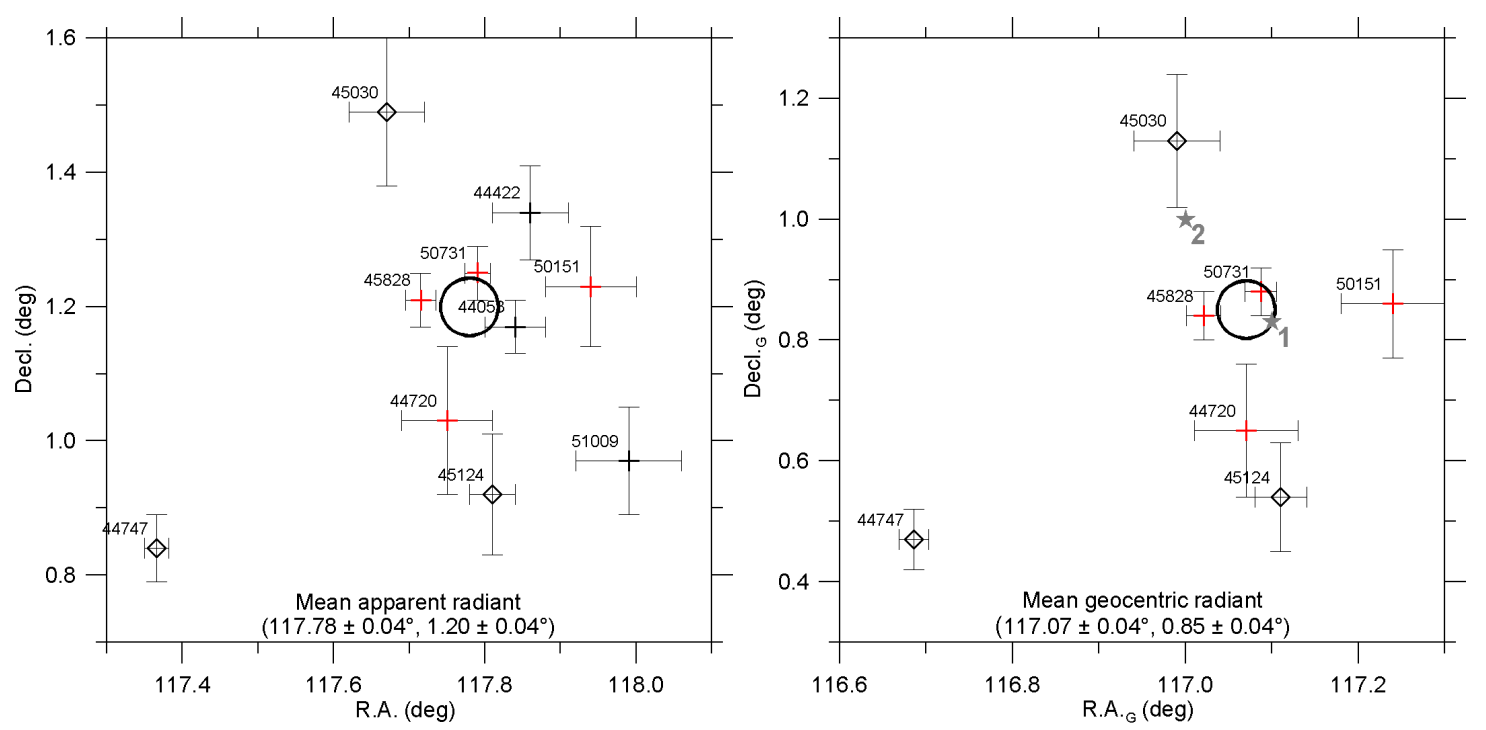

Fig. 2. Apparent (left panel) and geocentric (right panel) radiants (J2000.0) of the photographic (crosses) and video (diamonds) meteors of AMO 2019. The legend of the points is the beginning time (corresponding to data in Table 3). Red crosses show radiants of photographic meteors with available velocity measurements (for which the geocentric radiant and heliocentric orbit can be computed) and black circles show mean radiants (weighted average) of photographic meteors. Gray stars show geocentric radiants of sources 1 and 2 from Table 5 for comparison. The radiant of source 3 is out of the graph borders. Sizes of black circles correspond to the uncertainty of one standard deviation.

and $8500 \AA$ A , especially for fast meteors (Vojáček et al. 2015). Due to similar velocities, the relative intensities of atmospheric lines are similar for both spectra. The sodium, as the only significant meteoritic line visible in this spectral range, is present in the Perseid spectrum, but it is missing from the AMO spectrum. This is in an agreement with the work of Štork et al. (1998), as they observed a low amount of $\mathrm{Na}$ in the spectra of members of the AMO outburst on 1995 November 22. Borovička et al. (2005) concluded that AMO meteors fall near the boundary between $\mathrm{Na}$-poor and $\mathrm{Na}$-free meteoroids according to their spectral properties ( $\mathrm{Mg}-\mathrm{Na}-\mathrm{Fe}$ ratios). 
Table 5. Mean values of geocentric radiants and orbital elements of AMO meteors published so far.

\begin{tabular}{l|cccccccccc}
\hline Source & $\begin{array}{c}\text { R.A.G } \\
(\mathrm{deg})\end{array}$ & $\begin{array}{c}\text { Decl. } G \\
(\mathrm{deg})\end{array}$ & $\begin{array}{c}\mathrm{v}_{G} \\
\left(\mathrm{~km} \mathrm{~s}^{-1}\right)\end{array}$ & $\begin{array}{c}\mathrm{a} \\
(\mathrm{AU})\end{array}$ & $\mathrm{e}$ & $\begin{array}{c}\mathrm{q} \\
(\mathrm{AU})\end{array}$ & $\begin{array}{c}\omega \\
(\mathrm{deg})\end{array}$ & $\begin{array}{c}\Omega \\
(\mathrm{deg})\end{array}$ & $\begin{array}{c}\mathrm{i} \\
(\mathrm{deg})\end{array}$ & $\mathrm{T}_{J}$ \\
\hline 1 & 117.10 & 0.83 & 63.0 & 500 & 0.999 & 0.488 & 90.7 & 59.3 & 134.1 & -0.60 \\
2 & 117.0 & 1.0 & 62.6 & 43 & 0.989 & 0.474 & 92 & 59.527 & 134.0 & -0.49 \\
3 & 117.53 & 1.18 & 62.6 & & & 0.485 & 91.25 & 59.425 & 138.18 & \\
4 & 117.07 & 0.85 & 62.11 & 18.7 & 0.9745 & 0.4773 & 92.64 & 59.310 & 133.67 & -0.31 \\
5 & 116.81 & 0.57 & 62.5 & 44 & 0.989 & 0.485 & 91.1 & 59.307 & 133.3 & -0.47 \\
6 & 116.95 & 0.77 & 62.18 & 21 & 0.977 & 0.4788 & 92.4 & 59.307 & 133.59 & -0.34 \\
\hline
\end{tabular}

Note: Reference 1 is Jenniskens et al. (1997); 2 is Jenniskens $\mathcal{E}$ Odeh |2017); 3 is the annual component from Roggemans et al. 2018); 4 is from photographic data of this work; 5 is from video data of this work; 6 is from both video and photographic data of this work.

\section{Discussion}

We can confirm that the predicted outburst of the Alpha Monocerotid meteor shower occurred on 2019 November 22. The number of recorded meteors is not sufficient to compute an activity profile or meteoroid flux. The data of sensitive video cameras suggest a deficit of meteors fainter than magnitude +2 , but this result has low statistical significance. It would suggest a small population index, but $r=3.00 \pm 0.18$ was reported by Miskotte (2020) from visual data. On the other hand, the radio data from Belarus reported by Roggemans et al. (2020) showed only a small enhancement of echoes during the outburst, indicating that the outburst was indeed inconspicuous at small masses.

The computed radiants and heliocentric orbits match those reported for the 1995 and 2017 outbursts. The radiant of the annual component reported by Roggemans et al. (2018) lies at a somewhat larger right ascension and declination. The radiant in 2019 was quite compact, with a diameter of less than one degree. The semi-major axis and period of the shower and the parent comet remains unknown. Our nominal mean solution of the period is only 100 years, but the uncertainty is large, and much longer periods are possible as well.

The most important results come from spectroscopy and peculiar tendency of terminal heights. Our earlier observation that AMO meteoroids are deficient in sodium (Štork et al. 1998; Borovička et al. 2005) was confirmed. Borovička et al. (2005) identified three populations of Na-free meteoroids. The first population is of iron meteoroids, and the second one contains Sun-approaching meteoroids with small perihelia. Alpha Monocerotids do not belong to either of these. They belong to the third population, which feature meteoroids in Halley-type orbits. Nafree meteoroids in Halley-type orbits are mostly sporadic. Alpha Monocerotids is the only known meteor shower of this type. Borovička et al. (2005) proposed that these meteoroids originate from primordial cometary crusts, which were exposed to cosmic rays for a long period of time, and volatile elements including sodium were lost.

A new finding is that small and medium-sized AMO meteoroids finish their ablation at the same height in the atmosphere (near $90 \mathrm{~km}$ ). This is unusual because in other meteor showers terminal height decreases with increasing meteoroid mass and trajectory length. The beginning height usually increases with mass, except for Geminids, where it is nearly constant (Koten et al. 2004). Geminids are also partly deficient in sodium because of their proximity to the Sun. But Alpha Monocerotids behave differently, with the beginning height increasing and terminal height being constant, demonstrating that their physical structure is different from any major meteoroid stream.

The meteor at 4:58:28 UT is our brightest and best observed AMO 2019 meteor. It was recorded from three sites and also by
DAFO at Churáňov station, so it was possible to process this meteor using our standard procedures (Borovička 1990, Borovička et al. 1995: Ceplecha 1987). We determined the value of a PE coefficient that describes the fireball ablation ability (Ceplecha \& McCrosky 1976). The value of $\mathrm{PE}=-5.31$ lies on the border between types II and IIIA, which corresponds to meteoroids composed of carbonaceous chondrites or regular cometary material (Ceplecha 1988). Moreover, it is similar to the mean PE value of Perseids and September epsilon Perseids (Shrbený \& Spurný 2019). This meteor behaves like ordinary cometary meteoroids according to the PE criterion. However, this may just be a coincidence since its end height is not too different from Perseids of the same length (Fig. 11. Moreover, the PE criterion was originally developed for bright fireballs and may not be a fully appropriate measure for smaller meteoroids. The photometric mass of the 4:58:28 UT meteor was only $10^{-4} \mathrm{~kg}$.

The light curve of meteor at 4:58:28 UT is shown in Figure 4 Black crosses correspond to absolute (100 km distance) brightness from DAFO at Churáňov, and the gray curve corresponds to an intensity scan of the meteor on a spectral image from SDAFO at Churáňov. The meteor was not bright enough to be recorded by the DAFO radiometer. The light curve is without any significant flare, which corresponds to a material that did not break down suddenly into a large number of small grains in the later part of the trajectory (as bright Perseids often do). Nevertheless, the onset of the brightness is quite steep. The middle of the light curve is rather flat, with only a small increase in brightness. The fading at the end is steep again. Such a light curve does not correspond to a single ablating body, which would exhibit a steady brightness increase in the first three quarters of the trajectory and then somewhat steeper fading. The observed light curve could be explained by a disruption of the meteoroid into a large number of grains of similar sizes at the beginning, which then ablate independently and are all exhausted at similar heights, causing the sudden end of the meteor.

We therefore propose that AMO meteoroids are devolatilized but also very crumbly. Meteoroids of all sizes disrupt into grains at the beginning of the atmospheric entry. The grain size is a typical material property, so different meteoroids disrupt into similar grains. The end height depends on grain properties and does therefore not depend on the initial meteoroid size, at least up to a critical size. Larger meteoroids just produce more grains, which leads to greater brightness and earlier detection of the meteor. Meteoroids larger than the critical size may contain some larger grains or take longer to disrupt completely, so their end heights are progressively lower.

The comparison with small Perseids shows that Alpha Monocerotid grains must be more refractory than the Perseid material. The lack of volatiles causes the ablation temperature to be higher, and the beginning heights of Alpha Monocerotids 
are therefore lower. Perseids surely also fragment into grains, though possibly in a different way. Yet, the AMO grains must be either larger, denser, or more resistant, and they penetrate deeper. In this sense, the hypothesis of Jenniskens et al. (1997) that Alpha Monocerotids are stronger compared to other cometary meteoroids can be confirmed.

To get better insight into possible properties of AMO grains, we tried to model the light curve of the 4:58:28 UT meteor with the erosion model of Borovička et al. (2007), originally used for faint Draconid meteors. A model assuming disruption into grains of masses of about $10^{-8} \mathrm{~kg}$ near the beginning of the meteor was able to reproduce the light curve, but it produced a high deceleration of the meteor. The dynamics could be brought into rough agreement with the data if the grain release (erosion) started well before the observed beginning of the meteor (at heights around $115 \mathrm{~km}$ or more) and was finished near the meteor's beginning (Figure 5p. In that model, the grains were already partly decelerated at the observed meteor's beginning, so the actual entry speed was not the measured $62.93 \pm 0.12 \mathrm{~km} \mathrm{~s}^{-1}$ given in Table 3 , but $63.35 \pm 0.30 \mathrm{~km} \mathrm{~s}^{-1}$. The corresponding eccentricity would be $0.992 \pm 0.013$, corresponding to a semi-major axis of $65 \mathrm{AU}$ and an orbital period of 500 years, with large uncertainties.

The grain masses were about $2 \times 10^{-7} \mathrm{~kg}$ (uncertainty of about $50 \%$ ), corresponding to a diameter of about $0.5 \mathrm{~mm}$ for an assumed density of $3000 \mathrm{~kg} \mathrm{~m}^{-3}$. Such grain sizes are larger than for the vast majority of cometary meteoroids modeled with the erosion model (Borovička et al. 2007, 2014; Campbell-Brown et al. 2013, Vojáček et al. 2019). We note that the lack of small grains was found as a common property for Na-poor and Nafree meteoroids (Vojáček et al. 2019). The ablation coefficient was found to be $\approx 0.025 \mathrm{~s}^{2} \mathrm{~km}^{-2}$ (uncertainty of about $25 \%$ ), which is comparable with Draconids. The 4:58:28 UT meteor disrupted into $\approx 500$ grains (assuming the luminous efficiency of Pecina \& Ceplecha (1983)). A single grain would produce meteor with maximum absolute magnitude of about +4 .

The fact that the parent comet of Alpha Monocerotids has not been yet discovered may be simply because of its long period. Nevertheless, it is also possible that the comet is only weakly active and is still largely covered by its primordial crust.

\section{Conclusions}

We presented atmospheric trajectories and radiants of ten Alpha Monocerotid meteors observed by photographic and video techniques during the outburst on 2019 November 22. Velocities, magnitudes, and orbits were obtained for seven meteors, and one incomplete video spectrum was captured. The AMO activity was observed between $4 \mathrm{~h} 26 \mathrm{~m}$ and $5 \mathrm{~h} 23 \mathrm{~m} \mathrm{UT}$, with maximum rates from visual counts in the ten-minute interval centered at $4 \mathrm{~h} 50 \mathrm{~m}$ UT. The geocentric radiant was compact, with a diameter of less than one degree, and was centered at R.A. $G=$ $116.95 \pm 0.08^{\circ}$, Decl $_{G}=0.77 \pm 0.07^{\circ}$ (one sigma errors). The geocentric velocity was found to be $62.18 \pm 0.15 \mathrm{~km} \mathrm{~s}^{-1}$. The orbital period is 100 years, or possibly longer if the measured velocities were affected by deceleration, as it was found from detailed modeling of the brightest recorded AMO.

The most interesting aspects are the physical properties of Alpha Monocerotid meteoroids, which were found to be distinct from any other meteoroid stream analyzed so far. The observed meteor end heights were found to be distributed along a constant level of $90 \mathrm{~km}$ for all meteors with magnitudes between +4 and -2 and with atmospheric trajectory lengths up to $40 \mathrm{~km}$. We also confirmed that AMO meteoroids are deficient in sodium.

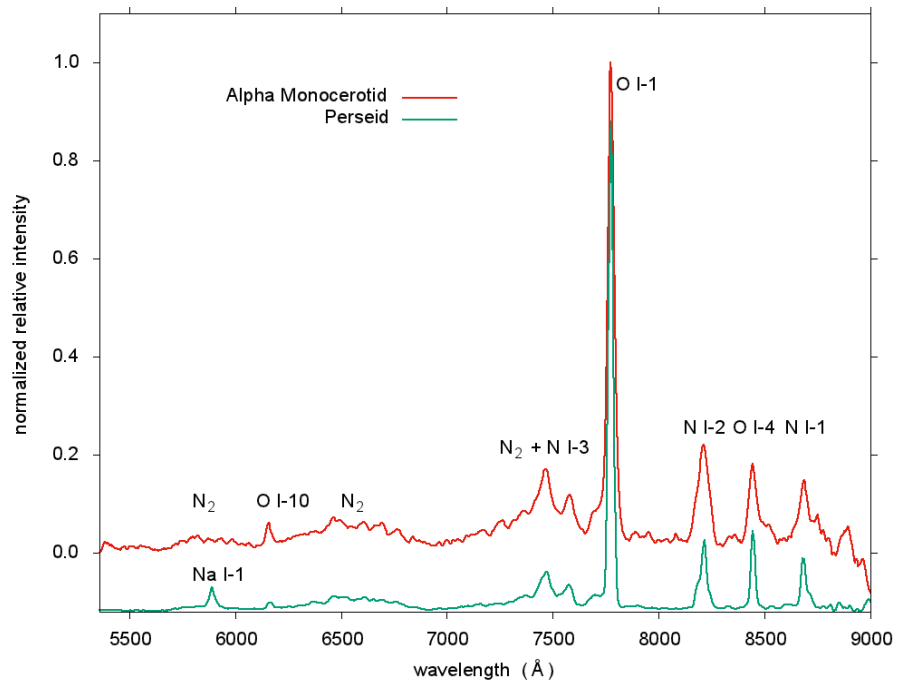

Fig. 3. Comparison between normalized calibrated spectra of Perseid and Alpha Monocerotid (5:01:51 UT) meteors. The spectrum of Perseid is shifted by 0.1 in intensity for clarity. No sodium Na I-1 and only weak molecular radiation of nitrogen $\mathrm{N}_{2}$ can be seen in the region between 5600 and $6100 \AA$ for the Alpha Monocerotid spectrum. The sodium is visible in the Perseid spectrum.

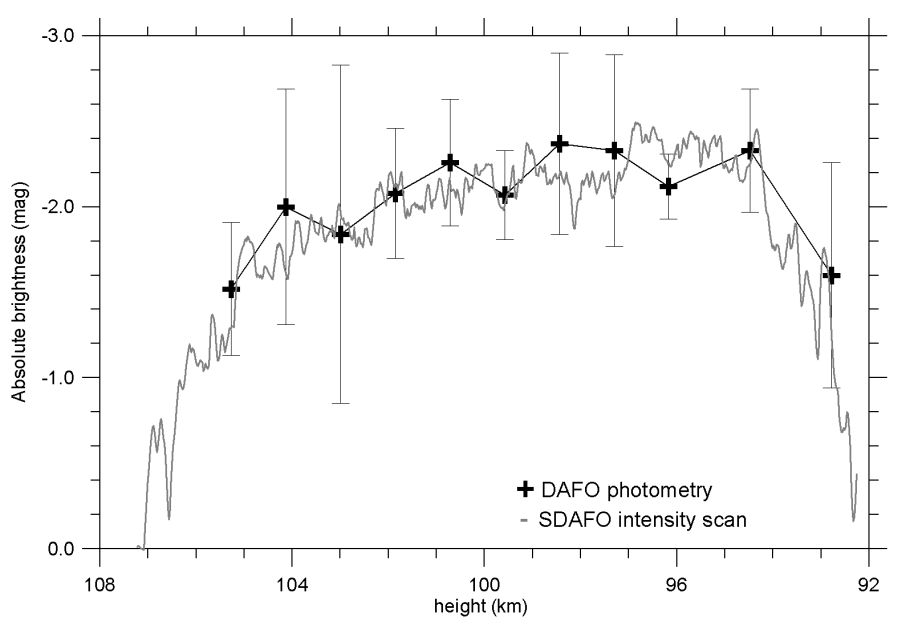

Fig. 4. Light curve of the brightest AMO meteor (4:58:28 UT) computed from DAFO photometry. The intensity scan on the SDAFO image was scaled to match the light curve. Small-scale variations are due to noise.

We propose that Alpha Monocerotids were formed from a devolatilized cometary crust that is structurally fragile and disintegrates into fundamental grains of a characteristic size of about $0.5 \mathrm{~mm}$ at the beginning of atmospheric entry. These grains are larger than grains of typical cometary meteoroids derived from active comets such as Perseids or Draconids.

Acknowledgements. We thank the staff of the Churáňov meteorological station operated by the Czech Hydrometeorological Institute for their assistance with the observing campaign. This work was supported by the institutional project RVO: 67985815 and grant no. 19-26232X from the Czech Science Foundation.

\section{References}

Borovička, J. 1990, Bulletin of the Astronomical Institutes of Czechoslovakia, 41,391

Borovička, J., Koten, P., Shrbený, L., Štork, R., \& Hornoch, K. 2014, Earth Moon and Planets, 113,15 


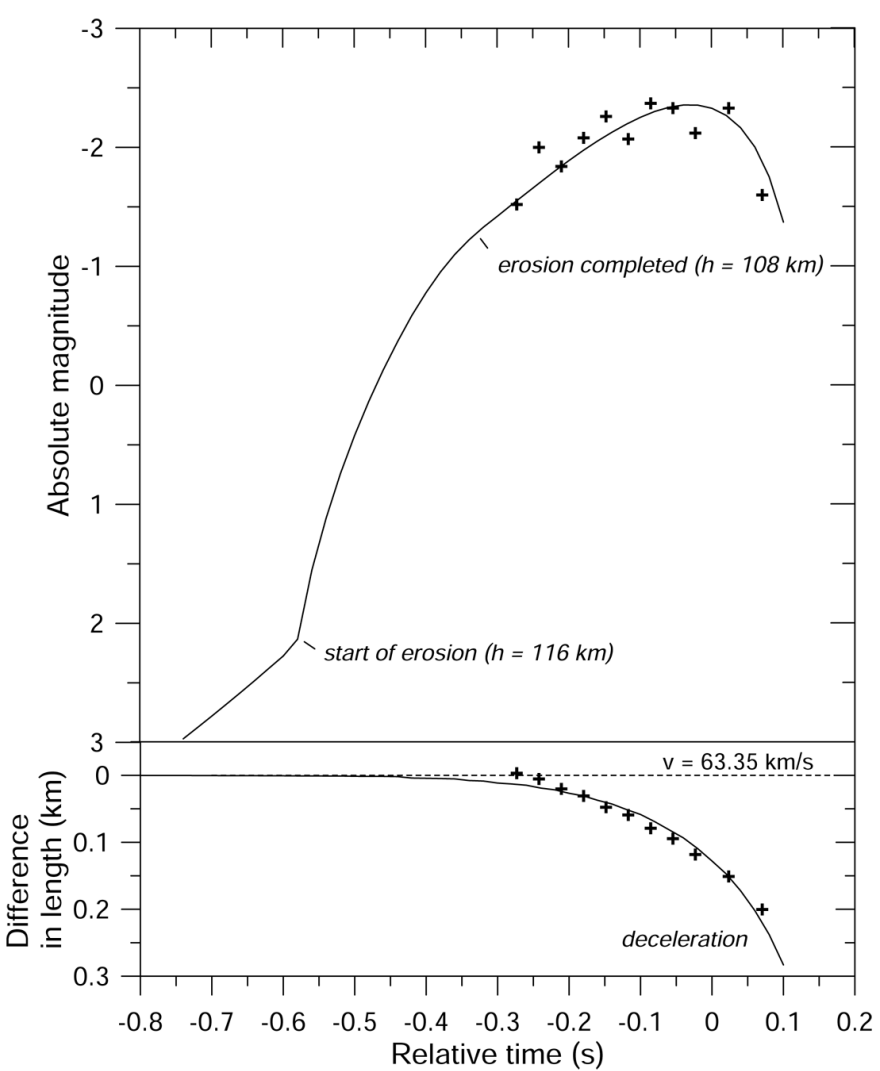

Fig. 5. Comparison of observed and modeled light curves (upper panel) and deceleration (lower panel) of the 4:58:28 UT meteor. Observed data are given as crosses, and the model is shown with smooth solid lines. Deceleration is expressed as the difference of the length along the trajectory (of the brightest part of meteor streak) at the given time from the length expected for constant meteor velocity of $63.35 \mathrm{~km} \mathrm{~s}^{-1}$. CIRA72 model atmosphere was used to compute the drag.

Borovička, J., Koten, P., Spurný, P., Boček, J., \& Štork, R. 2005, Icarus, 174, 15 Borovička, J. \& Spurný, P. 1995, WGN, Journal of the International Meteor Organization, 23, 203

Borovička, J., Spurný, P., \& Keclíková, J. 1995, A\&AS, 112, 173

Borovička, J., Spurný, P., \& Koten, P. 2007, A\&A, 473, 661

Borovička, J., Spurný, P., \& Shrbený, L. 2019, in International Meteor Conference 2018, ed. R. Rudawska, J. Rendtel, C. Powell, R. Lunsford, C. Verbeeck, \& A. Knöfel, 28-32

Campbell-Brown, M. D., Borovička, J., Brown, P. G., \& Stokan, E. 2013, A\&A, $557, \mathrm{~A} 41$

Ceplecha, Z. 1987, Bulletin of the Astronomical Institutes of Czechoslovakia, 38,222

Ceplecha, Z. 1988, Bulletin of the Astronomical Institutes of Czechoslovakia, 39,221

Ceplecha, Z. \& McCrosky, R. E. 1976, J. Geophys. Res., 81, 6257

Jenniskens, P. 2006, Meteor Showers and their Parent Comets (Cambridge University Press)

Jenniskens, P., Baggaley, J., Crumpton, I., et al. 2018, Planet. Space Sci., 154, 21

Jenniskens, P., Betlem, H., de Lignie, M., \& Langbroek, M. 1997, ApJ, 479, 441 Jenniskens, P. \& Lyytinen, E. 2019, Central Bureau Electronic Telegrams, 4692, 1

Jenniskens, P. \& Odeh, M. 2017, Central Bureau Electronic Telegrams, 4457, 1 Koten, P., Borovička, J., Spurný, P., Betlem, H., \& Evans, S. 2004, A\&A, 428, 683

Koten, P., Borovička, J., Vojáček, V., et al. 2020, Planet. Space Sci., 184, 104871 Lyytinen, E. \& Jenniskens, P. 2003, Icarus, 162, 443

Miskotte, K. 2020, eMeteorNews, 5, 186

Pecina, P. \& Ceplecha, Z. 1983, Bulletin of the Astronomical Institutes of Czechoslovakia, 34, 102

Roggemans, P., Howell, J. A. A., \& Gulon, T. 2020, eMeteorNews, 5, 13

Roggemans, P., Johannink, C., \& Biets, J.-M. 2018, eMeteorNews, 3, 12

Shrbený, L. \& Spurný, P. 2019, A\&A, 629, A137
Southworth, R. B. \& Hawkins, G. S. 1963, Smithsonian Contributions to Astrophysics, 7, 261

Spurný, P., Borovička, J., Mucke, H., \& Svoreň, J. 2017, A\&A, 605, A68

Štork, R., Borovička, J., Boček, J., \& Šolc, M. 1998, Meteoritics and Planetary Science Supplement, 33, A151

Vojáček, V., Borovička, J., Koten, P., Spurný, P., \& Štork, R. 2015, A\&A, 580, A67

Vojáček, V., Borovička, J., Koten, P., Spurný, P., \& Štork, R. 2019, A\&A, 621, A68

Znojil, V. \& Hornoch, K. 1995, WGN, Journal of the International Meteor Organization, 23, 205

Article number, page 8 of 8 